\title{
The SNAIL family member SCRATCH1 is not expressed in human tumors
}

\author{
JÉRÉMY BASTID ${ }^{1-3^{*}}$, BENJAMIN PIERRE BOUCHET $^{1-3^{*}}$, CLAIRE CIANCIA $^{1-3}$, JULIE POURCHET $^{1,2}$, \\ CAROLE AUDOYNAUD ${ }^{2}$, GAËL GRELIER ${ }^{1,2}$, ALAIN PUISIEUX ${ }^{1-3}$ and STÉPHANE ANSIEAU ${ }^{1,2}$ \\ ${ }^{1}$ Inserm U590; ${ }^{2}$ Centre Léon Bérard, Lyon; ${ }^{3}$ Université de Lyon, Lyon 1, ISPB, F-69008, France
}

Received June 12, 2009; Accepted August 20, 2009

\section{DOI: 10.3892/or_00000665}

\begin{abstract}
The SNAIL and SLUG transcription factors play important roles in embryogenesis owing to their anti-apoptotic properties and their ability to promote morphogenetic changes by inducing epithelial-mesenchymal transitions (EMT). These characteristics provide many of the proteins in these families with oncogenic and pro-metastatic capabilities when reactivated in cancers. The SCRATCH subgroup of the SNAIL superfamily, including SCRATCH1 and SCRATCH2, display distinct embryonic functions and diverge early in evolution. Despite the described overexpression of SCRT1 (encoding for SCRATCH1) in a small subset of human lung cancers, there is little data supporting a role of SCRATCH proteins in tumorigenesis. To further explore this possibility, we assessed SNAII (SNAIL), SNAI2 (SLUG) and SCRT1 (SCRATCH1) expression in a wide panel of human and murine tumors encompassing 151 primary tumors and 6 different cancer types, including melanomas and multiple different carcinomas. Whereas SNAII and SNAI2 are widely expressed in human and murine tumors, our results reveal that SCRTI transcripts are undetectable in nearly all of the examined tumors suggesting that SCRATCH1 plays a minor role, if any, in tumorigenesis. Our data therefore suggest that oncogenic properties are not shared by all SNAIL superfamily members but instead are specifically allotted to the SNAIL subgroup supporting the conclusions that SNAIL and SCRATCH subgroups are functionally divergent and strengthening the hypothesis that the oncogenic potential of SNAIL and SLUG proteins relies on the hijacking of their embryonic functions.
\end{abstract}

\section{Introduction}

The epithelial-mesenchymal transition (EMT) is a transdifferentiation process that switches a polarized epithelial

Correspondence to: Professor Alain Puisieux or Dr Stéphane Ansieau, Centre Léon Bérard, 28 rue Laennec, F-69008, France

E-mail: puisieux@lyon.fnclcc.fr

E-mail: ansieau@lyon.fnclcc.fr

${ }^{*}$ Contributed equally

Key words: SNAIL transcription factors, SCRATCH, tumorigenesis, epithelial-mesenchymal transition phenotype into a highly motile fibroblastoid or mesenchymal phenotype. Required for morphogenetic movements during the embryonic development, EMT is also suggested to play an important role in promoting cancer cell dissemination $(1,2)$. Additionally, we and others have shown that EMT was associated with the acquisition of stem-like properties $(3,4)$ and with the inhibition of inherent primary failsafe programs (5), suggesting a major role during primary tumor growth. In light of its emerging role in tumor progression, signaling pathways regulating EMT induction have been deeply investigated, highlighting a prevalent role of various developmental gene regulators including the SNAIL transcription factor superfamily $(6,7)$.

SNAIL superfamily members share a highly conserved carboxy-terminal DNA binding domain encompassing four to six zinc fingers, as well as an $\mathrm{N}$-terminal repression domain, known as the SNAG domain (6). Through these two structures, SNAIL proteins specifically bind to E-box responsive elements and by recruiting the corepressor $\mathrm{CtBP}$ inhibit their target genes $(8,9)$. The SNAIL superfamily encompasses five members, organized into two evolutionary and functionally distinct subgroups, namely the SNAIL subgroup, encompassing the SNAIL (SNAII), SLUG (SNAI2) and SMUC (SNAI3) proteins, and the SCRATCH subgroup, encompassing the two SCRATCH1 (SCRT1) and SCRATCH2 (SCRT2) proteins $(10,11)$. SNAIL and SLUG, the two most studied members of the family, are essential for neural crest and mesoderm formation in mouse and chick embryos, respectively (10-13). Downstream the CSF/c-kit signaling pathway, SLUG was also found to be a determinant for spermatogenesis, melanocyte development and hematopoietic progenitor cell survival (7). Down-regulation of SNAI2 expression is thus associated with various pigmentation disorders such as the Waardenburg syndrome and piebaldism, as well as human congenital anemia (14). Inversely, SNAI2 overexpression has been described in a large spectrum of human cancers including leukemia, esophageal carcinomas and mesotheliomas (14), wherein the SNAI2 encompassing region is frequently amplified (14). SNAI2 is expressed in human breast tumors (14), but normal mammary epithelial cells also display high levels of SNAI2 (15), therefore rendering the role of SLUG in breast tumorigenesis less clear. SNAII is also overexpressed in a wide panel of cancers including breast, colon and gastric cancers, hepatocellular carcinomas, melanomas and synovial sarcomas within which 
Table I. Sequences of primers and probes.

\begin{tabular}{|c|c|c|c|}
\hline & NCBI RefSeq & Primer sequence & Universal Probe (Taqman) Library \\
\hline ACTB & NM_001101.2 & $\begin{array}{l}\text { Forward: attggcaatgagcggttc } \\
\text { Reverse: ggatgccacaggactccat }\end{array}$ & $\# 11$ \\
\hline ATP6AP1 & NM_001183.4 & $\begin{array}{l}\text { Forward: tgcagctctctacctacttagatcc } \\
\text { Reverse: ctgtgaaatcctcaatgctcag }\end{array}$ & $\# 1$ \\
\hline CFL1 & NM_005507.2 & $\begin{array}{l}\text { Forward: gtgccctctccttttcgttt } \\
\text { Reverse: ttgaacaccttgatgacaccat }\end{array}$ & $\# 5$ \\
\hline GAPDH & NM_002046.3 & $\begin{array}{l}\text { Forward: agccacatcgctcagacac } \\
\text { Reverse: gcccaatacgaccaaatcc }\end{array}$ & $\# 60$ \\
\hline$G U S B$ & NM_000181.2 & $\begin{array}{l}\text { Forward: cgccetgcctatctgtattc } \\
\text { Reverse: tccccacagggagtgtgtag }\end{array}$ & \#57 \\
\hline HPRTI & NM_000194.1 & $\begin{array}{l}\text { Forward: tgaccttgatttattttgcatacc } \\
\text { Reverse: cgagcaagacgttcagtcct }\end{array}$ & $\# 73$ \\
\hline PGK1 & NM_000291.2 & $\begin{array}{l}\text { Forward: ctgtggcttctggcatacct } \\
\text { Reverse: cttgctgctttcaggacca }\end{array}$ & \#42 \\
\hline$P P I B$ & NM_000942.4 & $\begin{array}{l}\text { Forward: acttcaccaggggagatgg } \\
\text { Reverse: agccgttggtgtctttgc }\end{array}$ & $\# 20$ \\
\hline TUBAIC & NM_032704.2 & $\begin{array}{l}\text { Forward: cccettcaagttctagtcatgc } \\
\text { Reverse: cattgccaatctggacacc }\end{array}$ & \#58 \\
\hline$U B B$ & NM_018955.2 & $\begin{array}{l}\text { Forward: aggatcctggtatccgctaac } \\
\text { Reverse: tcacattttcgatggtgtcact }\end{array}$ & \#39 \\
\hline SNAII & NM_005985 & $\begin{array}{l}\text { Forward: gctgcaggactctaatccaga } \\
\text { Reverse: atctccggaggtgggatg }\end{array}$ & $\# 11$ \\
\hline SNAI2 & NM_003068 & $\begin{array}{l}\text { Forward: tggttgcttcaaggacacat } \\
\text { Reverse: gttgcagtgagggcaagaa }\end{array}$ & $\# 7$ \\
\hline SCRTI & NM_031309.4 & $\begin{array}{l}\text { Forward: tcaaacttgacgcgttctcttcgg } \\
\text { Reverse: agtcgctgaggtaccctttatcgt }\end{array}$ & None \\
\hline
\end{tabular}

it is invariably associated with dedifferentiation and invasiness (16-23). Additionally, SNAIL was shown to be required for tumor growth and metastatic properties of human breast and mouse skin carcinoma cell lines $(24,25)$ and associated with recurrence of breast tumors (26). Reactivation of each of SNAII or SNAI2 genes has been associated with the acquisition of invasive properties due to their ability to induce an EMT $(7,27)$. Interestingly, SNAIL stabilization by TNF- $\alpha$ through $\mathrm{NF}-\kappa \mathrm{B}$ activity was recently shown as a primary mechanism by which tumor-associated macrophages (TAMs) might promote tumor cell motility (28). Their anti-apoptotic properties might also contribute to their oncogenic potential. Indeed, SNAIL expression in MDCK epithelial cells induces an EMT associated with resistance to serum-deprivation or TNF- $\alpha$-induced apoptosis (27). SLUG was also shown in hematopoietic precursor cells to function downstream p53 as a critical switch that prevents their apoptosis by antagonizing the transactivation of PUMA gene (BBC3) by p53 (29).
Despite their sequence homology (around 60\% identity with SLUG and SNAIL C-terminal zinc-fingers), SCRATCH proteins functionally diverge from SNAIL and SLUG. In Drosophila, Scrt is exclusively expressed in dividing neuronal precursors and persists in post-mitotic neurons (30). Similarly, in the mouse, Scrt1 is only expressed in neural tissues and in the adult nervous system (31). Expression of Scrt2 during mouse development is even more restricted to cells that appear to be migrating radially to the neocortex and the hippocampus and in the cortical subventricular zone that gives rise to glial cells. Its expression progressively decreases, to be virtually undetectable in the adult brain (32). In light of these divergences and knowing that the SCRATCH proteins constitute an evolutionary distinct subgroup of the SNAIL superfamily $(10,11)$, we sought to investigate whether tumor promoting properties are shared by all SNAIL superfamily members or rather restricted to the SNAIL subgroup. The detection of SCRT1 transcripts in a small subset of lung 
carcinomas (31) and the anti-apoptotic properties of the C. elegans SCRATCH ortholog Ces-1 (33) argue in favor of a role of SCRATCH proteins in tumorigenesis. To further explore this hypothesis, we assessed the expression of genes from each subgroup, namely SCRT1, SNAI1 and SNAI2 in a wide panel of human and murine primary tumors. Our results first confirmed the reactivation of SNAII and SNAI2 in multiple human cancers. In contrast, with the exception of a handful of breast tumors, we failed to detect SCRT1 transcripts in any of the carcinomas and melanomas examined therefore excluding a preponderant role in human cancers. Further analyses of murine mammary tumors from the MMTV-ERBB2/Neu mouse model strengthened the conclusion that SCRATCH1 is unlikely to play a role in tumorigenesis. Overall, these results suggest that oncogenic properties are specifically allotted to the SNAIL subgroup of the SNAIL superfamily.

\section{Materials and methods}

$m R N A$ extraction and reverse transcription. Total mRNA was extracted using TriReagent ${ }^{\circledR}$ (Sigma) and Phase Lock $\mathrm{Gel}^{\circledR}$ (Eppendorf) according to the instructions of the manufacturer. mRNA $(1 \mu \mathrm{g})$ was reverse transcribed using the First-strand cDNA Synthesis ${ }^{\circledR}$ (Amersham Bioscience/GE Healthcare).

Gene expression analysis in human primary tumors. Taqman quantitative PCR analysis was carried out on a LightCycler ${ }^{\circledR}$ 2.0 System (Roche Applied Science) at least in triplicates. Housekeeping genes (ACTB, ATP6AP1, CFL1, GAPDH, GUSB, HPRT 1, PGK1, PPIB, TBP, TFRC, TUBAIC and $U B B$ ) were used for normalization of target mRNA expression in each sample type. They were selected by systematic geNorm analysis as previously described (34). Real-time specific intron-spanning PCR assays were designed using the ProbeFinder software (Roche Applied Science). Transcription was compared with normal tissues provided by the Biologic Resource Center of the Centre Léon Bérard and/or commercial RNA (Clontech). An average between independent sources was used as a reference (indicated as Norm-Mean) in lung, kidney, colon and ESCC tumors. In breast tumors and melanomas, expression was normalized using human mammary epithelial cells (indicated as Norm) and three independent sources of normal human melanocytes (Melanocyte-mean) respectively as references.

SCRT1 transcription was assessed by SYBR green quantitative PCR. Expression was compared with an average between independent sources in kidney and colon cancers. No SCRT1 expression was detected in ESCC, lung tumors and melanomas as well as their normal counterparts. As no $S C R T 1$ transcript was expressed in normal mammary epithelial cells, relative expression of SCRT1 in breast tumors is displayed in arbitrary units.

Sequences of primers and probes are listed in Table I.

Gene expression analysis in MMTV-ErbB2/Neu transgenic mice-derived tumors. SYBR green quantitative PCR was performed using $R p l p O$ (encoding for 36B4) as an internal control gene. Relative expression is displayed in arbitrary
Table II. Sequences of specific murine primer pairs.

\begin{tabular}{|c|c|c|}
\hline & NCBI RefSeq & Primer sequence \\
\hline RplpO & NM_007475 & $\begin{array}{l}\text { Forward: gctgatgggcaagaacacca } \\
\text { Reverse: ccggatgtgaggcagcagtt }\end{array}$ \\
\hline Snail & NM_011427 & $\begin{array}{l}\text { Forward: caccctcatctgggactctc } \\
\text { Reverse: gcttttgccactgtcctcat }\end{array}$ \\
\hline Snai2 & NM_011415 & $\begin{array}{l}\text { Forward: cagctccactccactctcct } \\
\text { Reverse: tgaaccactgtgatccttgg }\end{array}$ \\
\hline Scrt1 & NM_130893 & $\begin{array}{l}\text { Forward: agacctcgacagctcctacg } \\
\text { Reverse: ccccacgtagtcactgaggta }\end{array}$ \\
\hline
\end{tabular}

units. Sequences of specific murine primer pairs are listed in Table II.

\section{Results}

In order to evaluate the role of the SNAIL family transcription factor SCRATCH1 in tumorigenesis, SNAI1, SNAI2 and SCRT1 expression was assessed by qRT-PCR in 132 human primary tumors encompassing 6 different cancer types and 19 murine primary mammary tumors. Accurate expression analysis was performed using the Taqman or SYBRgreen technology and a combination of 12 housekeeping genes selected by systematic geNorm analysis (34).

SNAI1 and SNAI2 are widely expressed in human primary tumors. Confirming previous work (35), SNAII was found to be overexpressed (at least twice the expression of the corresponding normal tissue, dashed line) with high frequencies in breast tumors (overexpression: 97\%, 0- to 72-fold, $\mathrm{n}=78$; Fig. 1a) regardless of the subtype examined (in situ carcinoma, invasive ductal carcinomas or invasive lobular carcinomas), strengthening the hypothesis of its crucial role in breast tumorigenesis. SNAI2 was not overexpressed in breast cancers compared to normal human mammary epithelial cells (overexpression: 0\%, 0.1- to 1.8-fold, n=78; Fig. 1a). However, analysis of relative amount of SNAI2 mRNA confirmed that both normal human mammary epithelial cells and breast tumors in fact display high SNAI2 expression (Fig. 1a, inset graph) (15). In accordance with previous work, expression of SNAI1 and SNAI2 was increased in a significant proportion of esophageal squamous cell carcinomas (overexpression: $73 \%, 0.8$ - to 4.2-fold for SNAII, and 80\%, 0.9- to 5.4-fold for SNAI2, n=15, respectively; Fig. 2a) (36) and SNAII was found to be overexpressed in melanomas (overexpression: $60 \%, 0$ - to 212-fold, n=10; Fig. 2c, left graph) $(23,36)$. SNAI2 transcripts are detectable at a similar high rate in both melanocytes and melanomas (Fig. 2c, right graph), wherein it was suggested to genetically program melanomas to metastasize (37). We additionally confirmed SNAII and revealed the previously undescribed $S N A I 2$ overexpression in colon (overexpression: 44\%, 0.5- to 8.2-fold for SNAI1, and 33\%, 0.4- to 28.9-fold for $S N A I 2$, n=9; Fig. 2d) and kidney cancers 

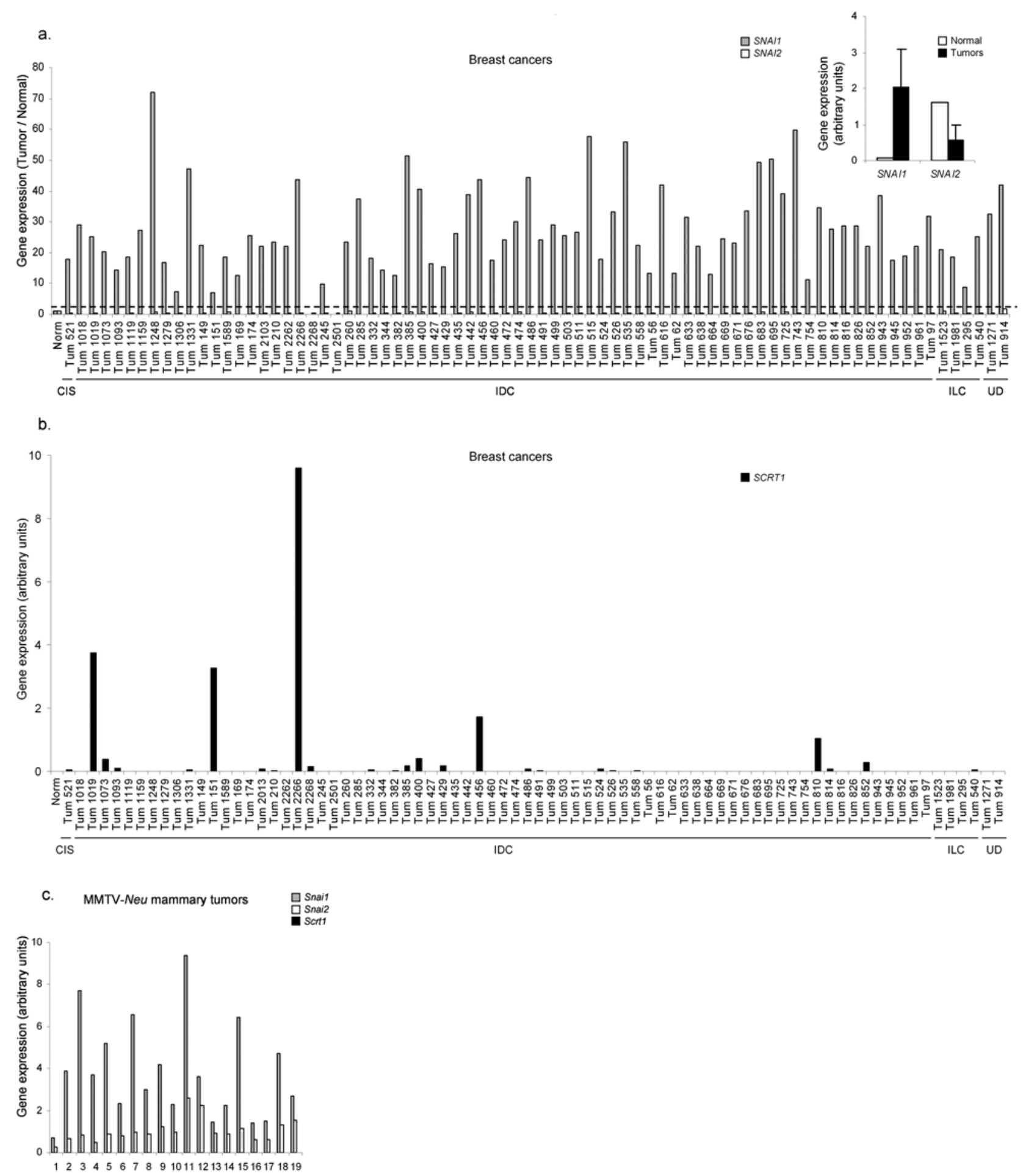

Figure 1. Expression analysis of SNAIL family genes in human and murine breast tumors. (a) SNAII and SNAI2 transcription was assessed by qRT-PCR in human breast tumors and normalized using normal human mammary epithelial cells. Relative amounts of transcripts are shown. CIS, carcinoma in situ; IDC, invasive ductal carcinomas; ILC, invasive lobular carcinomas; UD, undefined. Inset graph displays relative amounts of SNAII and SNAI2 mRNA to the normalizer genes in human mammary epithelial cells (Normal) and breast tumors (Tumors). (b) SCRT1 transcription was assessed by qRT-PCR in human breast tumors and human mammary epithelial cells. Relative amounts of SCRT1 mRNA to the normalizer genes are shown. CIS, carcinoma in situ; IDC, invasive ductal carcinomas; ILC, invasive lobular carcinomas; UD, undefined. Of note, as SCRT1 could not be detected in normal epithelial cells, expression is thus displayed in arbitrary units. (c) Murine Snai1, Snai2 and Scrt1 transcription was assessed by qRT-PCR in MMTV-ERBB2/Neu transgenic mice-derived mammary tumors. Relative amounts of mRNA to the normalizer gene are shown.

(overexpression: 62\%, 0.3- to 19.9-fold for SNAII, and 38\%, 0.1- to 41.6-fold, for $S N A I 2, \mathrm{n}=13$; Fig. 2e). Finally, both genes were found transcriptionally inactive in lung tumors (Fig. 2b).
SCRT1 is not expressed in human carcinomas and melanomas. SCRT1 mRNA was undetectable in ESCC, lung carcinomas, melanomas as well as in the corresponding normal tissues of origin (Fig. 2a-c) and was barely detectable in colon and 


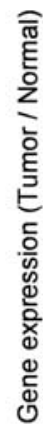

a.

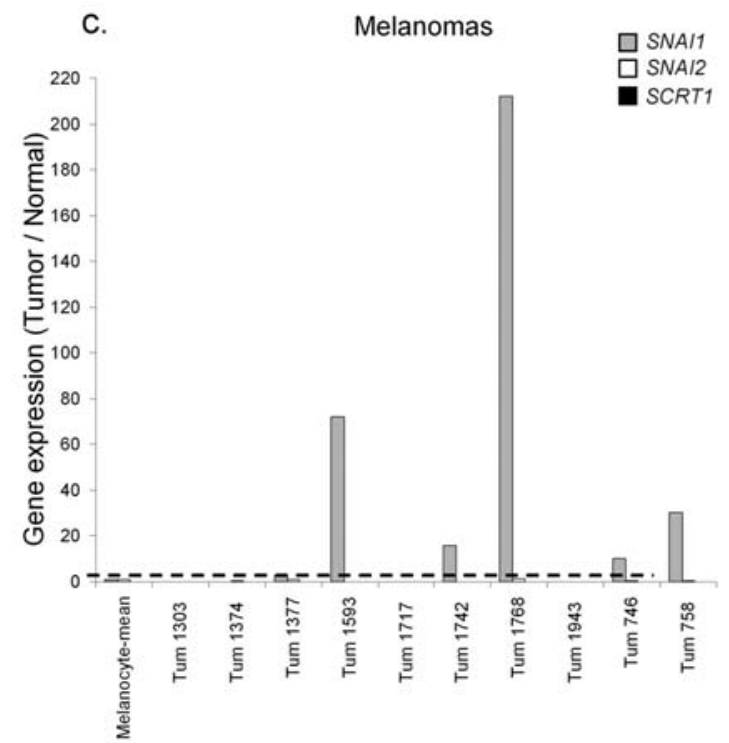

d.

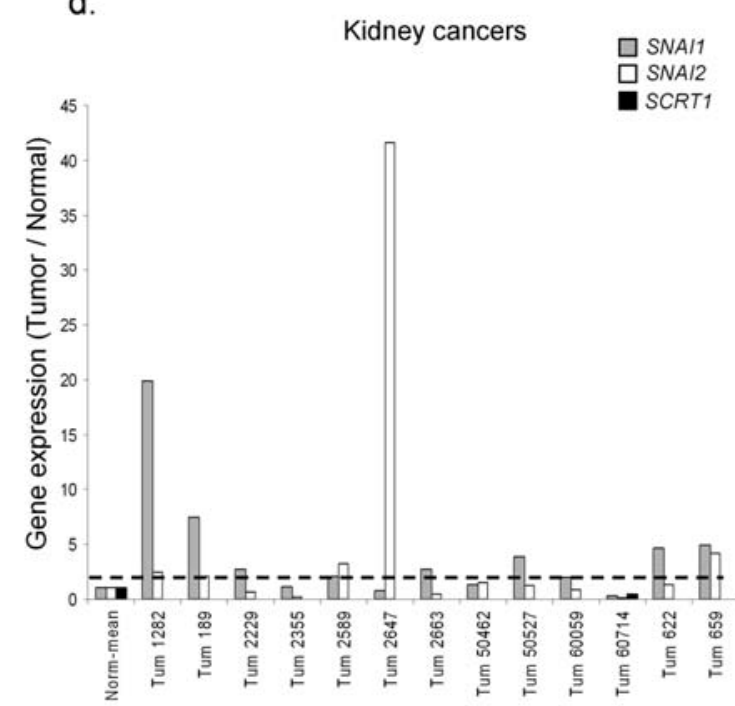

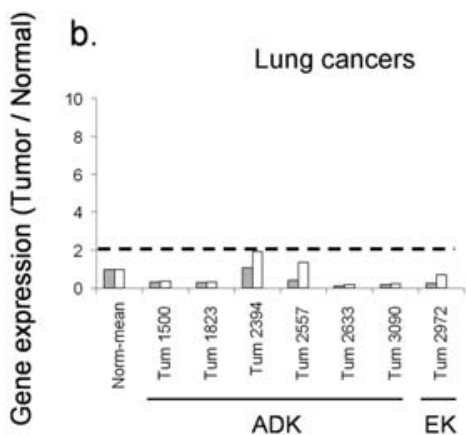

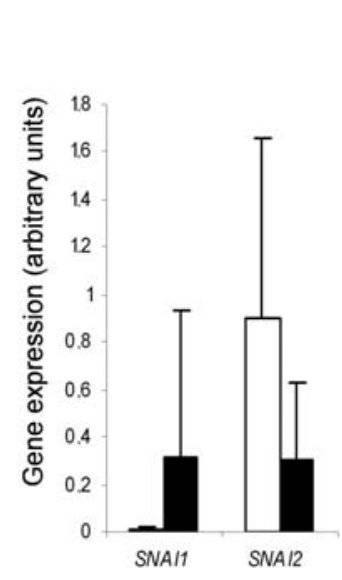

$\square$ Melanocytes

Melanomas

e.

Colon cancers

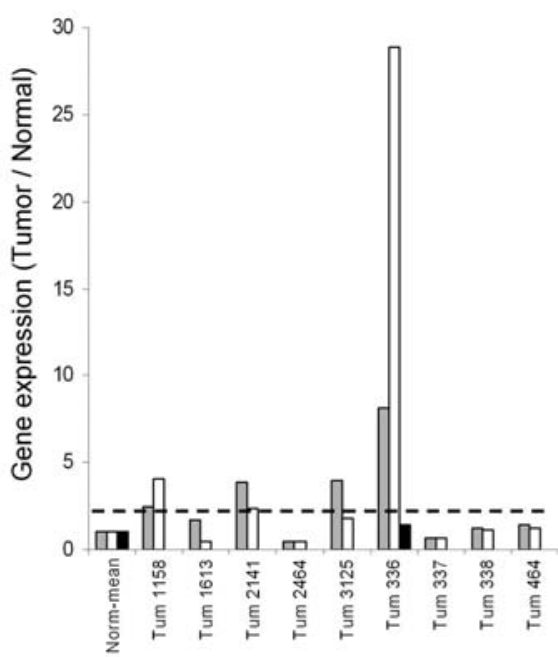

Figure 2. Expression analysis of Snail family genes in human tumors. (a-f) SNAI1, SNAI2 and SCRT1 transcription in (a) esophageal squamous cell carcinoma (ESCC), (b) lung cancers; ADK, adenocarcinomas; EK, epidermoid carcinomas, (c) melanomas, (d) kidney cancers and (e) colon cancers was assessed by qRT-PCR and normalized with that of healthy tissues or normal cell counterparts (Norm). Of note, SCRT1 could not be amplified in normal esophageal squamous epithelium, normal lung and melanocytes and the corresponding tumors. Inset graph in (c) (right) displays relative amounts of SNAII and SNAI2 mRNA to the normalizer genes in melanocytes and melanomas.

kidney cancer specimens (Fig. 2d and e). In breast cancers, SCRT1 mRNA was mainly undetectable although SCRT1 mRNA could be amplified in 5 out of 78 tumor samples (Fig. 1b). Because of the limited and overall low expression of SCRT1 in human breast tumors, we therefore speculated that SCRATCH1 must have a minor role, if any, in breast carcinogenesis. To substantiate our conclusion, we next assessed Snail, Snai2 and Scrt1 expression in 19 freshly 
isolated murine mammary tumors derived from an MMTV$E R B B 2 / N e u$ mouse transgenic model (expressing the $E R B B 2 / N e u$ proto-oncogene under the control of the MMTV promoter) (38). In accordance with our results in human breast tumors, Snail and Snai2 transcripts were found to be expressed in MMTV-ERBB2/Neu mouse derived tumors (Fig. 1c). However, no expression of Scrtl could be detected in these tumors, again supporting the idea that SCRATCH1 does not play a role in breast carcinogenesis.

\section{Discussion}

The SNAIL and SLUG transcription factors are believed to promote cancer progression through their ability to promote EMT and to protect cells from apoptosis, properties reminiscent to their embryonic functions (6). Despite their evolutionary and functional divergence $(10,11)$, several observations supported the hypothesis that oncogenic potential could also be allotted to the SCRATCH subgroup of the family. Indeed, SCRT1 transcripts were detected in a small subset of lung carcinomas (31). Additionally, C. elegans SCRATCH ortholog Ces-1, likewise SNAIL and SLUG, was shown to display anti-apoptotic properties (33). To further explore this hypothesis, we investigated the expression of the Snail family related gene SCRT1, SNAII and SNAI2 in a wide panel of human tumors as well as in murine mammary tumors. Our results clearly established that, whereas SNAII and SNAI2 are widely overexpressed in many human cancers, SCRT1 transcripts remained undetectable in most human cancers examined. Of note, we failed to detect $S C R T 1$ transcription in a set of lung adenocarcinomas and epidermoid carcinomas (Fig. 2a), strengthening the exclusivity of its previously described expression in small cell lung carcinomas with neuroendocrine (NE) features (31). As SCRT1 is implicated in the maintenance of NE features, one can however assume that its expression in small cell lung carcinomas with NE features reflects the NE phenotype of these cells rather than a role in lung carcinogenesis.

It is noteworthy that SCRT1 expression was detectable in a small subset of breast human cancers ( 5 out of 78 ; Fig. 1b) and in a limited number of human breast tumor cell lines ( 2 out of 15; data not shown). These data suggest that SCRATCH1 is unlikely to play a role in breast tumorigenesis. The rare expression observed in some breast tumors could rather reflect the presence of NE cells where SCRATCH1 is known to be functional (31); a hypothesis requiring further confirmation. However, using the Oncomine multiple array comparison software (www.oncomine.org), we found that SCRT1 mRNA is not enriched in tumors with NE features and does not take part of the neuroendocrine signature.

The lack of detectable SCRT1 expression in the large panel of human tumors examined is likely to exclude a role of SCRATCH1 in carcinogenesis and melanomagenesis. As phylogenetic and embryonic expression analysis demonstrated that SCRATCH (SCRATCH1 and SCRATCH2) and SNAIL (SNAIL, SLUG and SMUC) proteins constitute evolutionary and functionally distinct subgroups (10), one could presume that only the hijacking of SNAIL subgroup functions may provide cancer cells with a selective advantage. However, as a neuronal specific network might be essential for reactivating SCRTI expression, a specific role in promoting neuronal-derived tumorigenesis could not be excluded. Further investigations, including domain-swap chimera experiments, are warranted to definitively clarify the point.

\section{Acknowledgements}

The authors thank George Hinkal for his help in manuscript preparation and scientific discussions. We also thank Eric Tabone (Centre de Ressources Biologiques, Centre Léon Bérard, Lyon, France) and Elisabeth Brambilla for providing tumor samples. This study was supported by the Ligue Contre le Cancer (Comité du Rhône et Comité de l'Ain). BPB is a recipient of a scholarship from the Fondation pour la Recherche Médicale (FRM).

\section{References}

1. Lee JM, Dedhar S, Kalluri R and Thompson EW: The epithelialmesenchymal transition: new insights in signaling, development, and disease. J Cell Biol 172: 973-981, 2006.

2. Thiery JP: Epithelial-mesenchymal transitions in tumour progression. Nat Rev Cancer 2: 442-454, 2002.

3. Mani SA, Guo W, Liao MJ, et al: The epithelial-mesenchymal transition generates cells with properties of stem cells. Cell 133: 704-715, 2008.

4. Morel AP, Lievre M, Thomas C, Hinkal G, Ansieau S and Puisieux A: Generation of breast cancer stem cells through epithelial-mesenchymal transition. PLoS one 3: e2888, 2008.

5. Ansieau S, Bastid J, Doreau A, et al: Induction of EMT by twist proteins as a collateral effect of tumor-promoting inactivation of premature senescence. Cancer Cell 14: 79-89, 2008.

6. Nieto MA: The snail superfamily of zinc-finger transcription factors. Nat Rev Mol Cell Biol 3: 155-166, 2002.

7. Peinado H, Olmeda D and Cano A: Snail, Zeb and bHLH factors in tumour progression: an alliance against the epithelial phenotype? Nat Rev Cancer 7: 415-428, 2007.

8. Grimes HL, Chan TO, Zweidler-McKay PA, Tong B and Tsichlis PN: The Gfi-1 proto-oncoprotein contains a novel transcriptional repressor domain, SNAG, and inhibits G1 arrest induced by interleukin-2 withdrawal. Mol Cell Biol 16: 6263-6272, 1996.

9. Nibu Y, Zhang H, Bajor E, Barolo S, Small S and Levine M: $\mathrm{dCtBP}$ mediates transcriptional repression by Knirps, Kruppel and Snail in the Drosophila embryo. EMBO J 17: 7009-7020, 1998.

10. Barrallo-Gimeno A and Nieto MA: Evolutionary history of the Snail/Scratch superfamily. Trends Genet (In press).

11. Barrallo-Gimeno A and Nieto MA: The Snail genes as inducers of cell movement and survival: implications in development and cancer. Development 132: 3151-3161, 2005.

12. Nieto MA, Sargent MG, Wilkinson DG and Cooke J: Control of cell behavior during vertebrate development by Slug, a zinc finger gene. Science 264: 835-839, 1994.

13. Carver EA, Jiang R, Lan Y, Oram KF and Gridley T: The mouse snail gene encodes a key regulator of the epithelialmesenchymal transition. Mol Cell Biol 21: 8184-8188, 2001.

14. Cobaleda C, Perez-Caro M, Vicente-Duenas C and SanchezGarcia I: Function of the zinc-finger transcription factor SNAI2 in cancer and development. Annu Rev Genet 41: 41-61, 2007.

15. Come C, Arnoux V, Bibeau F and Savagner P: Roles of the transcription factors snail and slug during mammary morphogenesis and breast carcinoma progression. J Mammary Gland Biol Neoplasia 9: 183-193, 2004.

16. Blanco MJ, Moreno-Bueno G, Sarrio D, Locascio A, Cano A, Palacios J and Nieto MA: Correlation of Snail expression with histological grade and lymph node status in breast carcinomas. Oncogene 21: 3241-3246, 2002.

17. Elloul S, Elstrand MB, Nesland JM, et al: Snail, Slug, and Smad-interacting protein 1 as novel parameters of disease aggressiveness in metastatic ovarian and breast carcinoma. Cancer 103: 1631-1643, 2005.

18. Rosivatz E, Becker I, Specht K, et al: Differential expression of the epithelial-mesenchymal transition regulators snail, SIP1, and twist in gastric cancer. Am J Pathol 161: 1881-1891, 2002. 
19. Sugimachi K, Tanaka S, Kameyama T, et al: Transcriptional repressor snail and progression of human hepatocellular carcinoma. Clin Cancer Res 9: 2657-2664, 2003.

20. Miyoshi A, Kitajima Y, Kido S, Shimonishi T, Matsuyama S, Kitahara K and Miyazaki K: Snail accelerates cancer invasion by upregulating MMP expression and is associated with poor prognosis of hepatocellular carcinoma. Br J Cancer 92: 252-258, 2005 .

21. Palmer HG, Larriba MJ, Garcia JM, et al: The transcription factor SNAIL represses vitamin D receptor expression and responsiveness in human colon cancer. Nat Med 10: 917-919, 2004.

22. Saito T, Oda Y, Kawaguchi K, et al: E-cadherin mutation and Snail overexpression as alternative mechanisms of E-cadherin inactivation in synovial sarcoma. Oncogene 23: 8629-8638, 2004.

23. Poser I, Dominguez D, De Herreros AG, Varnai A, Buettner R and Bosserhoff AK: Loss of E-cadherin expression in melanoma cells involves up-regulation of the transcriptional repressor Snail. J Biol Chem 276: 24661-24666, 2001.

24. Olmeda D, Montes A, Moreno-Bueno G, Flores JM, Portillo F and Cano A: Snai1 and Snai2 collaborate on tumor growth and metastasis properties of mouse skin carcinoma cell lines. Oncogene 27: 4690-4701, 2008.

25. Olmeda D, Moreno-Bueno G, Flores JM, Fabra A, Portillo F and Cano A: SNAI1 is required for tumor growth and lymph node metastasis of human breast carcinoma MDA-MB-231 cells. Cancer Res 67: 11721-11731, 2007.

26. Moody SE, Perez D, Pan TC, et al: The transcriptional repressor Snail promotes mammary tumor recurrence. Cancer Cell 8: 197-209, 2005

27. Vega S, Morales AV, Ocana OH, Valdes F, Fabregat I and Nieto MA: Snail blocks the cell cycle and confers resistance to cell death. Genes Dev 18: 1131-1143, 2004.

28. Wu Y, Deng J, Rychahou PG, Qiu S, Evers BM and Zhou BP: Stabilization of snail by NF-kappaB is required for inflammationinduced cell migration and invasion. Cancer Cell 15: 416-428, 2009.
29. Wu WS, Heinrichs S, Xu D, Garrison SP, Zambetti GP, Adams JM and Look AT: Slug antagonizes p53-mediated apoptosis of hematopoietic progenitors by repressing puma. Cell 123: 641-653, 2005.

30. Roark M, Sturtevant MA, Emery J, Vaessin H, Grell E and Bier E: scratch, a pan-neural gene encoding a zinc finger protein related to snail, promotes neuronal development. Genes Dev 9: 2384-2398, 1995 .

31. Nakakura EK, Watkins DN, Schuebel KE, Sriuranpong V, Borges MW, Nelkin BD and Ball DW: Mammalian scratch: a neural-specific Snail family transcriptional repressor. Proc Natl Acad Sci USA 98: 4010-4015, 2001.

32. Marin F and Nieto MA: The expression of Scratch genes in the developing and adult brain. Dev Dyn 235: 2586-2591, 2006.

33. Metzstein MM and Horvitz HR: The C. elegans cell death specification gene ces-1 encodes a snail family zinc finger protein. Mol Cell 4: 309-319, 1999.

34. Vandesompele J, De Preter K, Pattyn F, Poppe B, van Roy N, De Paepe A and Speleman F: Accurate normalization of realtime quantitative RT-PCR data by geometric averaging of multiple internal control genes. Genome Biol 18: 3, 2002.

35. Come C, Magnino F, Bibeau F, De Santa BP, Becker KF, Theillet $C$ and Savagner P: Snail and slug play distinct roles during breast carcinoma progression. Clin Cancer Res 12: 5395-5402, 2006

36. Uchikado Y, Natsugoe S, Okumura H, Setoyama T, Matsumoto M, Ishigami S and Aikou T: Slug expression in the E-cadherin preserved tumors is related to prognosis in patients with esophageal squamous cell carcinoma. Clin Cancer Res 11: 1174-1180, 2005.

37. Gupta PB, Kuperwasser C, Brunet JP, et al: The melanocyte differentiation program predisposes to metastasis after neoplastic transformation. Nat Genet 37: 1047-1054, 2005.

38. Guy CT, Webster MA, Schaller M, Parsons TJ, Cardiff RD and Muller WJ: Expression of the neu protooncogene in the mammary epithelium of transgenic mice induces metastatic disease. Proc Natl Acad Sci USA 89: 10578-10582, 1992. 